\title{
Evolution of distraction osteogenesis in the oral and maxillofacial surgery
}

\author{
R. J. Aravind ${ }^{1}$, T. Kavin ${ }^{2}$, R. Narendar ${ }^{3}$, S. P. Indra Kumar ${ }^{4}$, Anto Ashmi ${ }^{5}$ \\ ${ }^{1,2}$ Professor, ${ }^{3}$ Reader, ${ }^{4}$ Senior Lecturer, ${ }^{5}$ Intern, Dept. of Oral and Maxillofacial Surgery, Vivekanandha Dental College for Women, \\ Elaiyampalayam, Tamil Nadu, India
}

*Corresponding Author: R. J. Aravind

Email: kumarjeeth@yahoo.com

\begin{abstract}
Distraction osteogenesis which is also called as callus distraction orcallotasis is used to restore the skeletal deformities and in reconstructive surgery. Most commonly, it is carried out in the department of oral maxillofacial surgery, orthopaedics and paediatric surgery. It is a very favourable and effective method for stable long-term effects. The use of distraction osteogenesis is found to have increased multiple folds in the last decade. And this is attributed to its advantages like little relapse, bigger movements range, generation of soft tissue, less likelihood of nerve injury, less likelihood of idiopathic condylar resorption. Some important applications of distraction osteogenesis are as an alternative to conventional surgery for maxillary and mandibular lengthening and reconstruction of alveolar segmental defects after tumour resection before implant installation. ${ }^{1}$ The distracter devices are found to transfer forces and they act as a rigid support for bone consolidation to occur. In this article, an attempt has been made to review the evolution of distraction osteogenesis over eons.
\end{abstract}

Keywords: Distraction osteogenesis.

\section{Introduction}

Distraction osteogenesis which is seen as a farewell to major osteotomies and other surgeries, is the mechanical induction of bone that occurs between the vascular bony surfaces that are gradually pulled apart by gradual distraction. The new bones that has formed bridges the gap and remodels to normal bone macrostructure. It was developed by ilizarov in 1956. The other names are transosseous synthesis, osteodistraction, callotasis, callus distraction. Ilizarov paved way for distraction osteogenesis by his tension - stress principle, ${ }^{3,4}$ which states that gradual traction of the tissues creates stress that activates tissue growth and regenerate, the shape and mass of the bone are influenced by mechanical load and blood supply." "The principles offer details about

1. Minimal disturbance of bone

2. Delay before distraction

3. Rate and rhythm of distraction

4. Site of osteotomy

5. Unifocal or bifocal lengthening ${ }^{5}$

Ilizarov's technique when experimented in dogs showed various results. 7 groups were considered of which, groups 1, 2 and 3 differed in the type of fixation. Groups 4 and 5 showed variation in the amount of marrow. Groups 6 and underwent transverse distraction. The results obtained in the membrane bones were similar to that obtained in the long bones. From then on, it was successfully applied for limb lengthening, angular amd rotational deformities correction, fracture repair, malunions, nonunions etc., Thus, it is a process by which a bone formation can be brought about as a result of normal healing process. It is so advantageous that it serves as an alternative to or almost to orthognathic surgeries.

\section{Evolution}

Hippocrates was the first person in the history of medicine to work on the traction forces on broken bones. However, a force without interruption for long bone cracks can be found in the literature work by Chaulic in 1300A.D. This force was delivered with the help of a pulley system that consisted of a weight attached to the leg by a cord.

Surgical osteotomy was initially performed by Barton in 1826. However, it's fixation was attributed to Malgaigne, who constructed advice that transmitted direct force on to the bone. ${ }^{13}$ Snyder et al in 1972 resected a dog mandible and performed distraction successfully. Michelli and Mioti in 1977 carried out experiment in the canine mandibles. McCarthy in 1989 made the first attempt in humans for craniofacial distraction. Molina and Ortiz in 1995 used bidirectional vectors. McCarthy overruled them by proving the efficacy of multidirectional appliances. Guerrero in 1990 introduced intra oral appliances for arch expansion. In 1991, Ilizarov postulates were given that stated that the gradual traction creates stress that can stimulate and maintain regeneration and active growth of living tissues. The second Ilizarov principle states that the "Gradual traction of the tissues creates stress that activates tissue growth and regenerate, the shape and mass of the bone are influenced by mechanical load and blood supply." ${ }^{4,15}$ The concept originated in the early 1900's in the field of orthopaedics. It was initially abandoned due to its complications such as infections etc., Ilizarov, changed the scenario by introducing do as a treatment for fractures and non-unions of the long bones of Russian soliders. Snyder was the first one to prove this in the oral cavity (1973). Thereafter the technique has been in use as an alternative to many surgeries. The technique has now reached a greater level of satisfaction among the people as it reduces the want for grafting and the length of in-hospital admission.

The sequence of events now in practice is

1. Surgical fracture of deformed bone

2. Distractor introduction

3. Rest phase

4. Separation of opposite segments 


\section{Activation of distractor ${ }^{8}$}

Applications of distraction osteogenesis in the field of oral and maxillofacial surgery:

1. Maxillary Distraction

2. Mandibular Distraction

3. Craniofacial Distraction

\section{Maxillary Distraction Osteogenesis}

Congenital nasal, malar, infraorbital deficiencies, congenital clefts in lip and palate are some cases that require treatment by the maxillary distraction osteogenesis.

The treatment modalities, here, are aimed at Advancement of lower maxilla and midface at Le fort I \& Le fort III levels respectively, Use of distraction for remodelling by gradual separation along sutures and osteogenesis.

Rigid external fixator, maxillary sagital correction with face mask, premaxillary distraction osteogenesis with toothborne appliance, transpalatal distracter, modular internal distraction (MID) system are some of the maxillary distracters used.

\section{Mandibular Distraction Osteogenesis}

Treatment varies from Unilateral or bilateral distraction of mandible by advancement of the body for micrognathia to Vertical and horizontal distraction of bony segments of jaws to correct the discrepancy in occlusion. Frankfort modular distraction system, MD-DOS (mandibular distraction with a dynamic osteosynthesis system), ROD distraction devices are some of the mandibular distracters used.

\section{Craniofacial Distraction Osteogenesis}

Few syndromes that are found to be associated with craniofacial deficiency are Apert syndrome, Crouzons syndrome, Pfeiffersyndrome, Pierre-Robin syndrome, Treacher Collins syndrome, Goldenhar Brodie syndrome etc.

\section{Principles of Distraction Osteogenesis}

Cutting of the bone is termed as osteotomy. It dates back to 415B.C. It is used for the management of angular or rotational deformities of bone. Anterior segmental osteotomies:

Wassumund's, Wunderer's, Posterior segmental osteotomies, Le fort I osteotomy, Le fort II osteotomy, Le fort III osteotomy are few types of maxillary osteotomies practised.

Vertical subsigmoid osteotomy, Inverted L osteotomy, C-osteotomy, Intra oral sagittal split osteotomy, Subcondylar osteotomy, Anterior sub apicalosteotomy, Posterior subapical osteotomy, Total sub apical osteotomy are some methods of mandibular osteotomies.

\section{Latency Period}

A fine period that is used required for the formation of callus before bone formation .Ilizarov suggested 5-7 days, the device is not activated during this phase.

\section{Distraction Period}

Activates of the distractor should be done at this phase .this can be achieved by axial screw rotation with a movement of $0.25-0.5 \mathrm{~mm} /$ turn the success purely depends on the rate and frequency of distraction.2-4 activations daily with 1.0-1.5 $\mathrm{mm}$ distraction would be ideal.

\section{Consolidation Phase}

Stabilisation is the motive of this phase for which, a long period of immobilisation has to be achieved, the duration of the consolidation phase is around 4-12 weeks clinically, the consolidation phase is to be kept as twice as that of the activation phase.

\section{Remodelling Phase}

Post removal of distractor, fully functional load is applied followed by continuous shrinkage and remodelling. ${ }^{9}$

\section{Discussion}

Distraction osteogenesis is found to be a powerful tool in use today for a variety of requirements as mentioned. Its wide range of applications viz., maxillary, mandibular, craniofacial osteotomies are definitely a boon to the patients and the entire health care industry as well. Distraction histiogenesis, simultaneous distraction, transport distraction and alveolar distraction are the various types of distraction procedures. ${ }^{18}$ The distraction offered by the distracters instigates bone generation by mechanical stimulation. It can be accomplished by a series of biological processes like undifferentiated cells into osteoblasts, angiogenesis, bone calcification etc. ${ }^{6,7}$ Desired effect of distraction osteogenesis can be achieved with a conjunction of both biological and biomechanical actors. Series of events are as follows, Mechanical cutting of bone is done initially that's followed by bone induction. 1-3 days: From division of bone to the start of traction. Normal healing is characterised by organisation of hematoma followed by the bone end necrosis, angioinvasion and inflammatory phase. End of 2 weeks: Application of forces: Gap increase followed by the tension stress stimulation that causes the cellular changes, angiogenesis and fibroblast proliferation. End of 8-12 weeks: post removal of distractor: Complete mineralisation of the distraction regenerate and appearance of new bone. After 12 weeks: Complete remodelling. That includes the widening of the haversian systems and osteoclastic resorption.

Looking on to the historical perspective of distraction osteogenesis, Snyder et al in 1972 resected a dog mandible and performed distraction successfully. Michelli and Mioti in 1977 carried out experimental in the canine mandibles. McCarthy in 1989 made the first attempt in humans for craniofacial distraction. Molina and Ortiz in 1995 used bidirectional vectors. McCarthy overruled them by proving the efficacy of multidirectional appliances. Guerrero in 1990 introduced intra oral appliances for arch expansion. An important feature of it that has contributed to the versatility of distraction osteogenesis is the less invasiveness that has made it more comfortable and efficient in the younger age 
group. Difficulty of bone regeneration is encountered in patients receiving and in those who have received radiation therapy. Because irradiated region is found to have experienced hypocellularity, hypovascularity and hypoxia which consequently can be related to osteonecrosis. Application of distraction osteogenesis is found to be more and more effective in such cases. ${ }^{19}$ Aronson et al ${ }^{16}$ suggested the use of distraction osteogenesis and orthognathic surgery as well. Swennen et al have published the distraction osteogenesis experience in patients with craniofacial syndromes. ${ }^{21}$ Cohen et al were the first to describe about the distraction osteogenesis for patients with midface deformities. ${ }^{22}$ Distraction osteogenesis is proven to be an alternative approach for the TMJ reconstruction that employs the principles of transport distraction where the bone has to move away from the host bone on to the defected bone. ${ }^{17}$ Distraction osteogenesis was first applied to the mandible in the early 1990s by McCarthy et al. Vos et al have mentioned about the stability that was achieved in mandible for a longer duration after the combined treatment of bilateral sagital split osteotomy and distraction procedure. ${ }^{23}$ Another advancement is the computer assisted distraction osteogenesis which is used to construct $3 \mathrm{~d}$ models, predefine the sites to be osteotomised and to position the vectors..$^{20}$ However, specific selection, planning and implementation are needed for the expected outcome. Zakhary I et al suggested that distraction osteogenesis is found to be needed for anomalies that require early intervention. Also if the patient compliance is found to be poorer, cautions are to be taken. Master et $\mathrm{al}^{10}$ in 2010 , has mentioned about relapse, scarring, nerve and tooth injury, infection, device failure, fusion error, TMJ injury as complications of mandibular distraction osteogenesis. Mazzonetta et $\mathrm{al}^{11}$ suggested infection, parasthesia, tipping of disk, hyperplasia, dehiscence, screw fracture, device fracture etc., as potential complications of alveolar distraction osteogenesis. Von Bremen et $\mathrm{al}^{12}$ described instable screw, scar stricture, abscess, recession etc., as expected complications in management of midline distraction. Still, such a versatile technique in the field of dentistry with its less invasiveness, and its advancement in biotechnology and expertise, is definitely a boon. It offers a budding hope to all the patients with severe deformities of face.

\section{Conclusion}

A wide range of applications for distraction osteogenesis is certainly not an emerging need. Instead, those challenging conditions that stand against the conventional routine treatment modalities are to be considered and focussed under distraction osteogenesis.

\section{Source of Funding}

None.

\section{Conflict of Interest}

None.

\section{References}

1. Nuntanaranont T, Ann R. Distraction osteogenesis: Role and clinical applications in the maxillofacial region. Australas Coll Dent Surg. 2008;19:125-32.

2. Andrade N, Gandhewar T, Kalra R. Development and evolution of distraction devices: An overview. Ann Maxillofac Surg. 2011:1(1):58-65.

3. Ilizarov GA. The tension stress effect on the genesis and growth of tissues: Part I-The influence of stability of fixation and soft tissue preservation. Clin Orthop Relat Res. 1989:238:249-81.

4. Ilizarov GA. The tension stress effect on the genesis and growth of tissues: Part II- The influence of the rate and frequency of distraction. Clin Orthop Relat Res. 1989:239:26385 .

5. Hamdy RC. The use of the Ilizarov method in children for limb lengthening. Medscape Orthop Sports Med J. 1998:2(6).

6. Rachmeil A, Laufer D, Jackson IT, Lewinson D. Mid face membranous bone lengthening- A one year histological and morphological follow up of distraction Osteogenesis. Calcified Tissue Int. 1998:62:370-6.

7. Rachmeil A, Rozen N, Peled M, Lewinson D. Characterisation of Mississippi maxillary membranous bone formation during Distraction Osteogenesis. Plast Reconstr Surg. 2002:109:161120.

8. Natu SSr, Ali I. The biology of Distraction Osteogenesis for correction of mandibular and craniofacial defects: A review. Dent Res J (Isfahan). 2014;11(1):16-26.

9. Hariri F, Chin SY, Rengarajoo J, Foo QC, Abidin SNNZ, Badruddin AFA. Distraction osteogenesis in oral and craniomacillofacial reconstructive surgery: 2018. DOI:10.5772/intechopen.81055.

10. Master DL, Hianson PR, Gosain AK. Complications of mandibular distraction Osteogenesis. J Craniofac Surg. 2010:21:1565-70.

11. Mazzonetta R, Allais M, Maurette RWF, Morrero A. Retrospective study of the potential complications during alveolar distraction Osteogenesis in 55 patients. Int J Oral Maxillofac Surg. 2007;36(1):6-10.

12. Breman JV, Schafer D, Kater W, Reef S. Complications during mandibular mid line diatraction. Angle Orthod. 2008;8(1):20-4.

13. Sharma S, Abishekarathi, Mittal G, Ranjan R. Distraction Osteogenesis- Evolution and technique-An overview. J Dent Med Serv. 2016;12:(1):115-20.

14. Ilizarov GA. The principles of the Ilizarov method. Bull Hosp Jt Distraction Orthop Institution. 1988;48:1-11.

15. Ilizarov GA. Clinical applications of tension stress effect for limb lengthening. Clin Orthop Relat Res. 1990;(250):8-26.

16. Aronson I et al The histology of distraction Osteogenesis using different external fixators. Clin Orthop Relat Res. 1989:33:246-50.

17. Li G, Berven S, Simpson H, Triffitt JT. Expression of BHP-4 mRNA during distraction osteogenesis in rabbits. Acta Orthop Scand. 1998:69(4):420-5.

18. Chandra N, Shaik S, Bhargava S. Review on distraction Osteogenesis: A Boon to maxillofacial reconstruction. Int J Appl Dent Sci. 2018;4(2):44-8.

19. Zakhary I, Laing BM, Mirkhani Ma, El-makkawi H. Distraction Osteogenesis for correction of oral and Craniofacial deformities; 2017.

20. Imola MJ, Hamber DD, Thatcher G, Chowdhary K. The Versatility of Distraction Osteogenesis in Craniofacial Durgery. Arch Fac Plast Surg. 2002;4:8-12.

21. Swennen G, Schliephake H, Dempf R, Schierle H, Malavez C. Craniofacial distraction Osteogenesis: A ROL part I-clinical studies. Int J Oral Maxillofac Surg. 2011:30:89-103.

22. Cohen SR, Rutrick RE, Burnstein FD. Distraction Osteogenesis of the human craniofacial skeleton-initial 
experience with new distraction system. J Craniofac Surg. 1995:6:368-74.

23. Vos MD, Baas EM, J de Lange. Stability of mandibular advancement procedures: Bilateral sagittal split osteotomy versus distraction osteogenesis. Int J Oral Maxillofac Surg. 2009;38(1):7-12.

24. McCarthy JG, Schreiber J, Karp N, Thorne CH, Grayson BH Lengthening of human mandible by gradual distraction. Plast Reconstr Surg. 1992:89:1-10.
How to cite this article: Aravind RJ, Kavin T, Narendar R, Indra Kumar SP, Ashmi A. Evolution of distraction osteogenesis in the oral and maxillofacial surgery. Int $J$ Oral Health Dent 2020;6(1):1-4. 